\title{
Pediatric Chronic Rhinosinusitis: Unmet Needs
}

\author{
Russell J. Hopp
}

Department of Pediatrics, Division of Allergy, Pulmonology and Sleep Medicine, University of Nebraska Medical Center and Children's Hospital and Medical Center, Omaha, NE 68198, USA; rhopp@childrensomaha.org

Received: 29 April 2020; Accepted: 8 June 2020; Published: 10 June 2020

\begin{abstract}
Pediatric chronic rhinosinusitis (CRS) remains an elusive diagnostic medical condition, largely based on imperfect diagnostic criteria, lack of controlled studies of therapy, lack of measure for resolution, and lack of information of pediatric sinus microbiome dysbiosis. The true prevalence of pediatric CRS is unknown, and symptoms often over-lap with other diagnoses. We review the unmet needs in pediatric CRS, to highlight potential research opportunities to improve understanding and therapy of the disease process.
\end{abstract}

Keywords: sinusitis; chronic rhinosinusitis; pediatrics; children; adolescent

\section{Introduction}

A considerable body of medical literature has been written on pediatric chronic rhinosinusitis, with much of the state of the art summarized in a recent review [1]. Despite the weight of the information, there remain a number of controversial areas. The goal for this discussion will be to summarize the current status on areas of interest and/or dispute, and then outline the recommendations for clinical and/or basic research.

A reasonable place to initiate this discussion is a list of the manuscripts on pediatric rhinosinusitis (CRS) in the recent past, which will serve as backdrop to the lingering issues in pediatric CRS [1-12].

Excluded in this discussion is pediatric CRS that is associated with cystic fibrosis, immunodeficiency, immotile ciliary syndrome, and anatomical abnormalities. Fungal sinusitis has been recently reviewed in UpToDate, and is not included [13]. Adolescents with polyps and aspirin exacerbation of respiratory disease are exceedingly rare, and are not discussed here, but have had a recent review [2,14].

Focusing on conventional pediatric CRS, without major co-morbidities, the topics that remain as unmet needs include:

1. Radiological diagnosis methodology;

2. Best antibiotic treatment regime and duration of time;

3. Microbiology (Microbiome issues);

4. Assessment of resolution and follow-up.

Each topic will include an overview, the current pragmatic perspective, and potential research opportunities.

\section{Radiological Diagnosis Methodology}

\subsection{Overview}

Reviews and consensus statements on diagnostic modalities are recently summarized by Heath et al. [4] and Chandy et al. [12]. An otolaryngology focused consensus statement was 
published in 2014 [15]. A statement from the American College of Radiology from 2018 provides a similar perspective [16].

These manuscripts provide perspective on the diagnostic modalities in chronic rhinosinusitis in children; however, the radiology issues, limitations, radiation effects, and cost have been a constant theme for years $[4,12,15,16]$. The reviews do not support use of standard radiography of paranasal sinuses in children (Waters view) due to sensitivity and specificity issues (as compared to computerized tomography $(\mathrm{CT}))[4,12,15]$, or the confusion of plain films with upper respiratory tract infection edema [12]. Plain radiography (waters view only) has limitations of sensitivity and specificity (as compared to CT) [16], and further details of the history of sinus radiological assessment has been reviewed [10].

The otolaryngology statement mentions conventional radiography and CT scans and their limitations, and advocates for evaluation with nasal endoscopy [15].

The American College of Radiology perspective in 2018 placed radiography in CRS, magnetuc resonance imaging (MRI) with or without contrast, and CT with contrast as usually not appropriate; while CT without contrast as usually appropriate [16]. MRI is limited due to sedation and less anatomical detail [16].

\subsection{Pragmatic Perspective}

Depending on the experience of the provider, a careful history and physical is likely the best determinant of infectious CRS [1,10]. The treatment and follow-up plan should commence. The longitudinal decision on the resolution of CRS is discussed subsequently.

\subsection{Research Opportunities}

The previous limitations of a MRI, including cost, sedation and experience, has been weakened by a recent report of sinus MRI in young cystic fibrosis (CF) children (mean age 2.3 years) and controls [17]. Sinus and anatomical abnormalities were easily detected. In control children $17 \%$ had sinus mucosal swelling, versus $83 \%$ of CF children. The authors concluded the potential utility of MRI in CF children, but the protocol distinctly raises the promise of the procedure for assessing (pre-) post antibiotic intervention benefit. Exploration of limited MRI for CRS in children is a viable opportunity, especially if minimal or no sedation and limited views will suffice. In addition, tracking longitudinal MRI changes after a "sero-specific" rhinovirus would add information of mucosal changes, similar to the single source CT data of Gwaltney et al. [18].

\section{Best Antibiotic Treatment Regime and Duration of Time}

\subsection{Overview}

In large part the antibiotic regimen recommended for pediatric infections CRS has been circumscriptive, but stable for 25 years, as previously summarized [1]. Historically (prior century), the antibiotics selected were directed at the recognized or suspected microbiological overgrowth $[1,19]$. Bio-filming added to the complexity [18], and information about the sinus microbiome with a disruptive disease dybiosis could provide future therapeutic directives [19,20], but is not yet part of the current pediatric CRS landscape.

\subsection{Pragmatic Perspectives}

The primary antibiotic selection had previously, pre-21st century, shifted to Augmentin (amoxicillin/clavulanate potassium) [1]. Several recent reviews have used extensive search methodologies to summarize clinical studies of CRS in children, and both find the duration of therapy is generally three weeks, although longer is reasonable [1,21]. Alternatives for recalcitrant disease or allergy to penicillin have not been forthcoming, although second and third generation cephalosporins, Clindamycin and Trimethoprim-Sulfamethoxazole have been mentioned [1,21]. 


\subsection{Research Opportunities}

The potential role of limited-view MRI in CRS needs further investigation. Without an exact description of the pediatric CRS microbiome and/or less ambiguous radiological methodologies, using augmentative empirical therapeutic agents for enhancing primary resolution of CRS may also prove fruitful. Options of potential agents, was previously reviewed [10]. Coupling any one additive therapy to antimicrobial treatment with a (pre-) post therapy MRI for resolution could serve as a baseline. For example, adding oral steroids for 14 days with antibiotics for 21 days with imaging could build on existing data [22].

\section{Microbiomic Status of Pediatric CRS}

\subsection{Overview}

Microbiome identification has occurred in the lungs of pediatric cystic fibrosis [23], in in asthma [24] and phenotypic pediatric asthma [25], the nasopharyngeal space in infants with cystic fibrosis [26], the nasal space in normal children and infants $[27,28]$, in adults with CRS $[19,20,29,30]$, and limited information in adults and children with allergic rhinitis [31]. The gut microbiome plays an active role in respiratory homeostatis [32], as does the microbiome balance of nasal and lower airways in asthmatic children with exacerbations [33]. A microbiome repertoire analysis in pediatric infectious CRS has not been performed.

\subsection{Pragmatic Perspective}

The antibiotic therapies proposed for pediatric CRS in the previous century persists, largely based on standard culture standard culture techniques. It is uncertain if future microbiome data would adjust or modify these historical guidelines.

\subsection{Research Opportunities}

The ability to obtained sinus mucosal tissue for standard culture or microbiome testing is contingent on the surgical technique used, which also has an age as a co-factor. Recent reviews discuss surgical alternatives, and in the case of a primary adenoidectomy with or without a balloon septoplasty procedure scant sinus tissue/fluid would be available $[8,9,15,34-36]$. With a functional endoscopic approach, or maxillary wash (with puncture) tissue and fluid would be available $[8,9,15,34,35]$.

Pediatric Otolaryngolgical specialists will need to be at the vanguard, coupled with new and easier capture technology [28] to provide preliminary microbiomic data in pediatric CRS. Details of antibiotic used prior to surgery and duration off antibiotic before surgery would be valuable companion data. The microbiome obtained from the nose just prior to surgery could be a comparer (ipsilateral, contralateral or bilateral). The recently report of the disease burden of pediatric chronic sinusitis would appear to provide ample clinical material [37], either for base nasal microbiome determination, or surgical sinus specimen microbiome identification.

\section{Assessment of Resolution and Follow-Up}

\subsection{Overview}

Determining resolution is probably the least discussed domain in the CRS treatment paradigm, however, some potential aspects have been previously reviewed $[1,10]$.

\subsection{Pragmatic Perspective}

Mostly, surgical options for medical recalcitrant patients appear to be the current thought $[8,15]$. The resolution pathway forward in pediatric CRS, short of surgical intervention, has not been a priority $[8,15]$. 


\subsection{Research Opportunities}

A recent report provides a critical, largely unreported, perspective on the clinical and economic burden of pediatric CRS [37]. Using ambulatory care assessments from 2005 to 2012 the authors estimated $2 \%$ of all pediatric ambulatory visits are for chronic sinusitis [37]. This large number of potential subjects could provide a basis for investigators to sample for longitudinal benefits for therapy and pre and post therapy nasal biomic changes. This will further allow support for radiologic assessment, and pre-post surgical assessment.

Several studies point the way for investigators to use the available ambulatory population of pediatric CRS patients for clinical research. The methodology of rapid nasopharyngeal testing has been established [28], and a publication from 2019 reported on thirty-one children with acute sinusitis [38]. A population of 237 children were followed for a year. Asymptomatic samples for viruses were obtained, and re-sampled on the 3rd day of a new upper respiratory tract infection, and again when the acute sinusitis was diagnose third. Using viral detection technology, about a quarter of subjects shifted to a new virus at acute sinusitis presentation, as compared to the baseline symptomatic virus recovered. A longitudinally followed pediatric population for CRS would require a larger base, but could over-lap with the design of an acute sinusitis protocol.

Another recent manuscript, published in a pediatric journal [39], provides the assessment of an outcome measure to follow the course of an acute sinusitis, using an instrument published in 2017 [40]. The questionnaire developed for acute sinusitis has 8 domains of questions, scaled from never to extreme (6 point). Interestingly, the sinus radiography showed strong associations with the disease activity, in the first (Version 1) of two study groups [41]. A review of the questions shows over-lap with clinical correlates to acute sinusitis, but also clinical connectivity to chronic sinusitis, such as cough (day or night) or stuffy nose [1,4,5,7,42]. Cough is debated in some reviews, however [42]. It seems reasonable to suggest a similar scoring system for pediatric CRS with tie-back to nasal microbiome findings.

The radiological arm of assessment of pediatric CRS has been reviewed in this manuscript. Although the outcome measures reported $[39,40]$ showed good correlation to a radiological procedure, the American College of Radiology appropriateness for acute sinusitis in children is termed "usually" not appropriate [16].

Any future utilization of radiological procedures to assesses resolution of CRS should heed the unique findings of Gwaltney et al. in 1994 [18]. The importance of their findings were previously noted [1,42]. Using CT assessment of 31 adult volunteers before and after a confirmed viral rhinosinusitis, about $80 \%$ had abnormal maxillary findings at $2-3$ days post onset of symptoms, and of the 14 re-studied at radiological follow-up 13-20 days, only three of 14 had any residual findings, although the three outliers were improved from the first CT.

These findings would suggest a combination approach of a microbiome assessment coupled with pre-post MRI findings and symptom assessment scores could be feasible in a small number of pediatric patients with CRS. The timing of the post radiographic study could be delayed, but timed to symptom measurement resolution and/or microbiomic shift.

Finally, an antigenically intact lysate of 8 bacteria (Broncho-Vaxom), as an oral capsule, was used in an international study in children as a post antibiotic prophylactic therapy. The goal was to enhance systemic and (local) immunity, and compared to placebo some nasal and symptom score benefit over one year was seen in the active group [43].

\section{Conclusions}

This review of areas of pediatric sinusitis controversy has provided pathways for clinical based research that could open totally new information streams in pediatric CRS.

Funding: This research received no external funding.

Acknowledgments: The author acknowledges the critical review of Mohammed Asghar Pasha, M.D. 
Conflicts of Interest: No personal or financial support or commercial association or conflict is relevant to this submission.

\section{References}

1. Hopp, R.; Allison, J.; Brooks, D. Fifty Years of Chronic Rhinosinusitis in Children: The Accepted, the Unknown, and Thoughts for the Future. Pediatr. Allergy Immunol. Pulmonol. 2016, 29, 61-67. [CrossRef]

2. Hopp, R.J. Do Adult Forms of Chronic Rhinosinusitis exist in Children or Adolescents? Sinusitis 2017, $2,7$. [CrossRef]

3. Hopp, R.J. Pediatric Chronic Sinusitis: What are thou? A Clinical Opinion. Sinusitis 2017, 2, 6. [CrossRef]

4. Heath, J.; Hartzell, L.; Putt, C.; Kennedy, J.L. Chronic Rhinosinusitis in Children: Pathophysiology, Evaluation, and Medical Management. Curr. Allergy Asthma Rep. 2018, 18, 37. [CrossRef] [PubMed]

5. Hamilos, D.H. Problem-based learning discussion: Medical management of pediatric chronic rhinosinusitis. Am. J. Rhinol. Allergy 2016, 30, 113-121. [CrossRef] [PubMed]

6. Akdis, C.A.; Bachert, C.; Cingi, C.; Dykewicz, M.S.; Helings, P.W.; Naclerio, R.M.; Schleimer, R.P.; Ledford, D. Endotypes and phenpotypes of chronic rhinosinusitis: A PRACTALL document of the_European Academy of Allergy and Clinical Allergy and Immunolgy and the Amecican Academy of Allergy, Asthma \& Immunology. J. Allergy Clin. Immunol. 2013, 131, 1479-1490. [PubMed]

7. Silviu-Dan, F.; Fanny, S.-D. Pediatric Chronic Rhinosinusitis. Pediatr. Ann. 2014, 43, 201-209. [CrossRef] [PubMed]

8. Beswick, D.M.; Messner, A.H.; Hwang, P.H. Pediatric chronic rhinosinusitis management in rhinologists and pediatric otolaryngologists. Ann. Otol. Rhinol. Laryngol. 2017, 126, 634-639. [CrossRef] [PubMed]

9. Sewell, R.K. An Overview of Surgical Approaches to Pediatric Chronic Sinusitis for Primary Care Providers. Sinusitis 2018, 3, 4. [CrossRef]

10. Hopp, R.J. Diagnosing and Managing Chronic Pediatric Rhinosinusitis: Still more questions than answers. Arch. Immunol. Allergy 2019, 2, 35-41.

11. Hamilos, D.L. Pediatric chronic rhinosinusitis. Am. J. Rhinol. Allergy 2015, 29, 414-420. [CrossRef] [PubMed]

12. Chandy, Z.; Ference, E.; Lee, J.T. Clinical Guidelines on Chronic Rhinosinusitis in Children. Curr. Allergy Asthma Rep. 2019, 19, 14. [CrossRef] [PubMed]

13. Cox, G.M.; Perfect, J.R.; Bleier, B.S. Fungal Sinusitis; Mitty, J., Ed.; UpTodate: Waltham, MA, USA, 2020.

14. Tuttle, K.L.; Schneider, T.R.; Henrickson, S.E.; Morris, D.; Abonia, J.P.; Spergel, J.M.; Laidlaw, T.M. Aspirin-exacerbated respiratory disease: Not always "adult-onset". J. Allergy Clin. Immunol. Pract. 2016, 4, 756-758. [CrossRef] [PubMed]

15. Brietzke, S.; Shin, J.; Choi, S.; Lee, J.T.; Parikh, S.R.; Pena, M.; Prager, J.D.; Ramadan, H.; Veling, M.; Corrigan, C.; et al. Clinical Consensus Statement: Pediatric Chronic Rhinosinusitis. Otolaryngol. Head Neck Surg. 2014, 151, 542-553. [CrossRef] [PubMed]

16. Tekes, A.; Palasis, S.; Durand, D.J.; Pruthi, S.; Booth, T.N.; Desai, N.K.; Jones, J.Y.; Kadom, N.; Lam, H.F.S.; Milla, S.S.; et al. ACR Appropriateness Criteria ${ }^{\circledR}$ Sinusitis-Child. J. Am. Coll. Radiol. 2018, 15, S403-S412. [CrossRef] [PubMed]

17. Sommerburg, O.; Wielpütz, M.O.; Trame, J.P.; Wuennemann, F.; Optazaite, E.; Stahl, M.; Baumann, I. MRI Detects Chronic Rhinosinusitis in Infants and Preschool Children with Cystic Fibrosis. Ann. Am. Thorac. Soc. 2020, 17, 714-723. [CrossRef] [PubMed]

18. Gwaltney, J.; Phillips, C.; Miller, R.; Riker, D. Computed Tomographic Study of the Common Cold. N. Engl. J. Med. 1994, 330, 25-30. [CrossRef] [PubMed]

19. Drago, L.; Pignataro, L.; Torretta, S. Microbiological aspects of acute and chronic pediatric rhino sinusitis. J. Clin. Med. 2019, 8, 149. [CrossRef] [PubMed]

20. Pasha, M.A. State of the Art-Adult chronic rhinosinusitis microbiome: Perspective for future studies in pediatrics. Sinusitis 2018, 3, 1. [CrossRef]

21. Brook, I. The role of antibiotics in pediatric chronic rhinosinusitis. Laryngoscope Investig. Otolaryngol. 2017, 2, 104-108. [CrossRef] [PubMed]

22. Ozturk, F.; Bakirtas, A.; Ileri, F.; Turktas, I. Efficacy and tolerability of systemic methylprednisolone in children and adolescents with chronic rhinosinusitis: A double-blind, placebo-controlled randomized trial. J. Allergy Clin. Immunol. 2011, 128, 348-352. [CrossRef] [PubMed] 
23. Hampton, T.H.; Green, D.M.; Cutting, G.; Morrison, H.G.; Sogin, M.; Gifford, A.H.; Stanton, B.A.; O’Toole, G.A. The microbiome in pediatric cystic fibrosis patients: The role of shared environment suggests a window of intervention. Impact Soylent Consum. Human Microbiome Compos. 2014, 2, 14. [CrossRef] [PubMed]

24. Kozik, A.J.; Huang, Y.J. The microbiome in asthma. Role in pathogenesis, phenotype and response to treatment. Ann. Allergy Asthma Immunol. 2019, 122, 270-275. [CrossRef] [PubMed]

25. Pérez-Losada, M.; Authelet, K.; Hoptay, C.; Kwak, C.; Crandall, K.A.; Freishtat, R. Pediatric asthma comprises different phenotypic clusters with unique nasal microbiotas. Microbiome 2018, 6, 179. [CrossRef] [PubMed]

26. Prevaes, S.; Groot, K.M.D.W.-D.; Janssens, H.M.; Piters, W.A.A.D.S.; Tramper-Stranders, G.A.; Wyllie, A.L.; Hasrat, R.; Tiddens, H.A.; Van Westreenen, M.; Van Der Ent, C.K.; et al. Development of the Nasopharyngeal Microbiota in Infants with Cystic Fibrosis. Am. J. Respir. Crit. Care Med. 2016, 193, 504-515. [CrossRef] [PubMed]

27. Kumpitsch, C.; Koskinen, K.; Schöpf, V.; Moissl-Eichinger, C. The microbiome of the upper respiratory tract in health and disease. BMC Biol. 2019, 17, 87. [CrossRef] [PubMed]

28. Lopez, S.M.C.; Martin, J.M.; Johnson, M.; Kurs-Lasky, M.; Horne, W.T.; Marshall, C.W.; Cooper, V.S.; Williams, J.V.; Shaikh, N. A method of processing nasopharyngeal swabs to enable multiple testing. Pediatr. Res. 2019, 86, 651-654. [CrossRef] [PubMed]

29. Mahdavinia, M.; Keshavarzian, A.; Tobin, M.C.; Landay, A.L.; Schleimer, R.P. A comprehensive review of the nasal microbiome in chronic rhinosinusitis (CRS). Clin. Exp. Allergy. 2016, 46, 21-41. [CrossRef] [PubMed]

30. Chalermwatanachi, T.; Velasquez, L.C.; Bachert, C. The microbiome of the upper airways: Focus on chronic rhinosinusitis. World Allergy Organ. J. 2015, 8, 3. [CrossRef] [PubMed]

31. Rawls, M.; Ellie, A.K. The microbiome of the nose. Ann. Allergy Asthma Immunol. 2019, 122, 17-24. [CrossRef] [PubMed]

32. Wypych, T.P.; Wickramasinghe, L.C.; Marsland, B.J. The influence of the microbiome on respiratory health. Nat. Immunol. 2019, 20, 1279-1290. [CrossRef] [PubMed]

33. Zhou, Y.; Jackson, D.; Bacharier, L.B.; Mauger, D.; Boushey, H.; Castro, M.; Weinstock, G.M. The upper-airway microbiota and loss of asthma control among asthmatic children. Nat. Commun. 2019, 10, 5714. [CrossRef] [PubMed]

34. Gudis, D.A.; Soler, Z.M. Update on pediatric sinus surgery: Indictaions and outcomes. Curr. Opin. Otolaryngol. Head Neck Surg. 2017, 25, 486-492. [CrossRef] [PubMed]

35. Makary, C.D.; Ramadan, H.H. Pediatric sinus surgery for chronic rhinosinusitis. Oper. Technol. Otolayngol. Head Neck Surg. 2018, 29, 89-93. [CrossRef]

36. Ramadan, H.H.; Terrell, A.M. Balloon Catheter Sinuplasty and Adenoidectomy in Children with Chronic Rhinosinusitis. Ann. Otol. Rhinol. Laryngol. 2017, 119, 578-582. [CrossRef] [PubMed]

37. Gilani, S.; Shin, J.J. The burden and visit prevalence of pediatric chronic rhinosinusitis. Otolaryngol. Head Neck Surg. 2017, 157, 1048-1052. [CrossRef] [PubMed]

38. DeMuri, G.P.; Eickhoff, J.C.; Gern, J.C.; Wald, E.R. Clinical and Virological Characteristics of Acute Sinusitis in Children. Clin. Infect. Dis. 2019, 69, 1764-1770. [CrossRef] [PubMed]

39. Shaikh, N.; Wald, E.R.; Jeong, J.H.; Kurs-Lasky, M.; Nash, D.; Pichichero, M.E.; Hoberman, A. Development and Modification of an Outcome Measure to Follow Symptoms of Children with Sinusitis. J. Pediatr. 2019, 207, 103-108. [CrossRef] [PubMed]

40. Garbutt, J.M.; Gellman, E.F.; Littenberg, B. The development and validation of an instrument to assess acute sinus disease in children. Qual. Life Res. 1999, 8, 225-233. [CrossRef] [PubMed]

41. Shaikh, N.; Hoberman, A.; Kearney, D.H.; Colborn, D.K.; Kurs-Lasky, M.; Jeong, J.; Haralam, M.A.; Bowen, A.; Flom, L.L.; Wald, E.R. Signs and Symptoms That Differentiate Acute Sinusitis from Viral Upper Respiratory Tract Infection. Pediatr. Infect. Dis. J. 2013, 32, 1061-1065. [CrossRef] [PubMed]

42. Weinberger, M. Whither sinusitis? Clin. Ped. 2018, 57, 1013-1019. [CrossRef] [PubMed]

43. Chen, J.; Zhou, Y.; Nie, J.; Wang, Y.; Zhang, L.; Shi, Q.; Tan, H.; Kong, W. Bacterial lysate for the prevention of chronic rhinosinusitis recurrence in children. J. Laryngol. Otol. 2017, 131, 523-528. [CrossRef] [PubMed]

(C) 2020 by the author. Licensee MDPI, Basel, Switzerland. This article is an open access article distributed under the terms and conditions of the Creative Commons Attribution (CC BY) license (http://creativecommons.org/licenses/by/4.0/). 